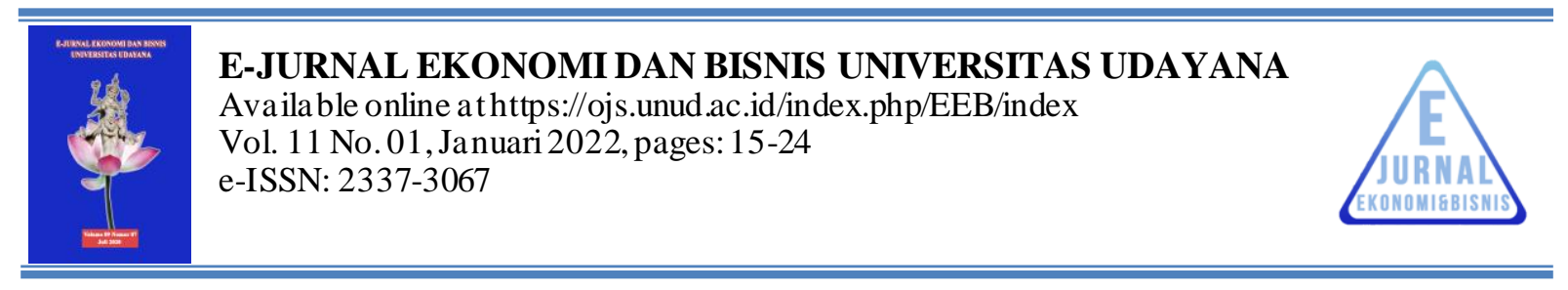

\title{
REAKSI PASAR MODALTERHADAP PERISTIWA PELANTIKAN KABINET INDONESIA MAJU HASIL RESHUFFLE JILID I TAHUN 2020
}

Ida Bagus Jelantik Tenaya ${ }^{1}$ I Wayan Ramantha ${ }^{2}$

\begin{tabular}{l}
\hline \multicolumn{1}{c}{ Article history: } \\
\hline Submitted: 29 Juli 2021 \\
Revised: 30 Agustus 2021 \\
Accepted: 7 September 2021 \\
\end{tabular}

Keywords:

Capital Market Reactions AbnormalReturns, Event Studies

\section{Kata Kunci:}

ReaksiPasar Modal; AbnormalReturn; StudiPeristiwa;

\section{Abstract}

This research was conducted on the Indonesia Stock Exchange on LQ45 indexed stocks. The dependent variable in this study is the market reaction which is measured by abnormal returns a round the date of the inauguration of the Indonesia Maju cabinet as a result of the reshuffle volume I in 2020. The number of samples taken is 43 companies, using purposive sampling technique. Data collection was carried out by archival research methods. Based on the results of the analysis, it was found that there was a significant difference in abnormal returns before and after the inauguration of the Indonesia Maju cabinet as a result of the 2020 reshuffle volume against the LQ45 indexed company shares listed on the IDX. This happened because the inauguration of the Indonesia Maju cabinet resulting from the 2020 reshuffle volume I contained information so that the market needed fast time to achieve a new balance. Investors in this study react quickly in absorbing information so that it is in accordance with the semistrong form of efficient market.

\begin{tabular}{|c|}
\hline Abstrak \\
\hline $\begin{array}{l}\text { Penelitian ini dilakukan di Bursa Efek Indonesia pada saham } \\
\text { terindeks LQ45. Variabel terikat dalam penelitian ini a dalah reaksi pasar } \\
\text { yang diukurdengan abnormalreturn di sekitar tanggal peristiwa pelantikan } \\
\text { kabinet Indonesia Maju hasil reshuffle jilid I tahun } 2020 \text {. Jumlah sa mpel } \\
\text { yang diambil sebanyak 43 perusahaan, dengan teknikpurposive sampling. } \\
\text { Pengumpulan data dilakukan dengan metodepenelitian arsip. Berda sarkan } \\
\text { hasil a nalisis ditemukanbahwa terdapat perbedaan yang signifikanabnormal } \\
\text { return sebelum dan sesudah peristiwa pelantikankabinet Ind one sia Maju } \\
\text { hasil reshuffle jilid I tahun } 2020 \text { terhadap jajaran saham perusaha an } \\
\text { terindeks LQ45 yang terdaftar di BEI. Hal ini terjadi karena peristiwa } \\
\text { pelantikankabinetIndonesia Maju hasil reshuffle jilid I tahun } 2020 \text { terdapat } \\
\text { kandungan informasi sehingga pasar membu tuh kan wak tu cepat dalam } \\
\text { pencapaian keseimbanganbaru. Investor dalam penelitian inibereaksicepat } \\
\text { dalam menyerap informasi sehingga sesuaidengan pasar efisien ben tuk } \\
\text { setengah kuat. }\end{array}$ \\
\hline
\end{tabular}

Fakultas Ekonomidan Bisnis,Universitas Udayana, Ba li, Indonesia ${ }^{2}$ 


\section{PENDAHULUAN}

Pasar modal merupakan pertemuan antara dua pihak yang memiliki kelebihan dana dengan pihak yang membutuhkan dana dengan cara memperjualbelikan sekuritas (Hall \& Kenjegaliev, 2016). Hal tersebut karena peran pasar modal sebagai sumber dana alternatif bagi kegiatan operasi perusahaan serta memberikan ruang bagi masyarakat dalam mengalokasikan dana yang dimilikinya untuk menghasilkan return melalui sektor-sektor yang produktif (E. P. Putra \& Wirawati, 2019). Sedangkan menurut Prameswari \& Wirakusuma (2018),pasar modal merupakan tempat bagi seseorang yang berkeinginan memanfaatkansejumlah dana miliknya untuk memperoleh keuntungan melalui suatu risiko tersendiri. Pasar modal akan efisien apabila instrumen informasi yang diperjual-belikan menunjukkan secara akurat nilai perusahaan termasuk kedalam prospek laba dan kualitas manajemennya (Pramiartini \& Sedana, 2021).

Pasar modal di Indonesia saat ini mengalami perkembangan yang baik. Menurutdata press release Bursa Efek Indonesia (BEI) pada tanggal 30 Desember 2020, menunjukkan sepanjang tahun 2020, jumlah investor di Pasar Modal Indonesia yang terdiri atas investor saham, obligasi, maupun reksadana mengalami peningkatan sebesar 56\% mencapai 3,87 juta Single Investor Identification (SID). Investor saham juga mengalami peningkatan sebesar 53\% menjadi sejumlah 1,68 juta SID. Penambahan jumlah investor di Indonesia menunjukkan bahwa masyarakatIndonesia saat ini menyadari akan pentingnya berinvestasi. Hal ini akan memberi dampak yang baik bagi perekonomian Indonesia, mengingat pasar modal juga berperan penting bagi perekonomian suatu negara. Semakin berkembang pasar modal pada suatu negara akan memperkencang pertumbuhan perekonomian di negara tersebut (Chandra \& Suardana, 2021). Pasar modal memiliki dua fungsi utama, yaitu fungsi ekonomi dan fungsi keuangan. Fungsi ekonomi dalam pasar modal adalah sarana untuk menghubungkan pihak yang memiliki dana lebih (investor) dengan pihak yang yang membutuhkan dana (Suhadak et al., 2019). Fungsi keuangan pasar modal adalah memberikesempatan kepada investor untuk mendapatkan return (keuntungan) sesuai dengan karakteristik investasi yang dipilih (Aryasa \& Suaryana, 2017).

Keuntungan yang didapat oleh investor ketika berinvestasi pada pasar modal khususnya saham berupa dividen dan capital gain. Selain keuntungan, terdapat juga beberapa risiko, yaitu capital loss dan likuidasi. Risiko investasi di pasar modal pada prinsipnya sangat terkait erat dengan terjadinya volatilitas harga saham, di mana naik turunnya harga saham ini dipengaruhi kondisi mikro dan makro ekonomi, kebijakan perusahaan, dan kinerja perusahaan (Mujib \& Candraningrat, 2021). Risiko tersebut dapat dicegah dengan mengamati sumber-sumber risiko dan setiap informasi yang mempengaruhi reaksi pasar modal (Juliani \& Sari, 2021). Informasi seringkali tidak dianggap remeh oleh para investor, hal ini biasanya dapat dilihat dari aktivitas jual beli dan harga saham atas suatu informasi atau peristiwa tertentu karena ini investor dapat bereaksi atas suatu informasi atau peristiwa yang dianggap bernilai. Informasi dapat dibagi menjadi dua yaitu informasi internal dan informasi eksternal (Fama, 1970). Informasi internal adalah informasi atas peristiwa yang terjadi di dalam perusahaan misalnya kebijakan ekspansi, kebijakan dividen dan kebijakan internal perusahaan. Sedangkan informasi eksternal adalah informasi atas peristiwa yang terjadi diluar kebijakan yang dibuat oleh perusahaan. Misalnya kebijakan dari pemerintah kepada perusahaan (Yasa \& Sari, 2020). Pengambilan keputusan selalu menyangkut masa depan yang mengandung ketidakpastian dan selalu menyangkut pemilihan suatu alternatif yang tersedia, oleh karena itu pengambilan keputusan investasi harus selalu berusaha mengumpulkan informasi dan mempertimbangkan masalah-masalah yang mungkin timbul dengan tepat waktu dan ketelitian untuk 
mengurangi ketidakpastian dalam proses pengambilan keputusanmengenai investasi (Osuala et al., 2018).

Informasi merupakan unsur penting dalam aktivitas para investor di pasar modal. Dengan adanya informasi yang relevan, para investor dapat memiliki gambaran terkait dengan risiko serta expected return yang berasal dari suatu sekuritas yang nantinya akan menetapkan sebuah keputusan dan menentukan strategi investasi untukmendapatkan hasil berupa tingkat pengembalian maksimal (Fiordelisi \& Galloppo, 2018). Informasi-informasi yangmenimbulkan reaksi pada pasar saham dan memengaruhi fluktuasi harga saham tidak hanya berasal dari informasi kondisi ekonomi, tetapi juga dapat berasal dari faktor- faktor lain non ekonomi seperti peristiwa hukum, peristiwa sosial dan gejolak politik dalam negeri yang berpengaruh pada pergerakan harga saham di Bursa Efek Indonesia (Nia, 2020).Hal ini dikarenakan kondisi politik yang stabil cenderung diikuti dengan kondisi ekonomi yang stabil sehingga membuat para investor merasa aman untuk menginvestasikan dananya di pasar modal Indonesia dan hal ini akan berdampak padameningkatnya kinerja ekonomi Indonesia (Gayatri \& Sari, 2018).

Salah satu peristiwa politik yang menarik diuji kandungan informasinya terhadap aktivitas di pasar modal Indonesia adalah peristiwa resmi pengumuman menteri Kabinet Indonesia Maju periode 2019-2024. Peristiwa politik seperti perombakan susunan kabinet (reshuffle) pada umumnya tidak sulit diduga karena tanda-tanda awal akan dilakukannya reshuffle dapat dilihat melalui berbagai isu akibatkinerja dari beberapa menteri yang kurang maksimal (Nuryana, 2017). Reshuffle kabinet tidak berpengaruh secara langsung terhadap pasar modal, tetapi informasi mengenai peristiwa ini dapat diserap oleh para pelaku pasar modal dan memengaruhi pengambilan keputusan para investor yang pada akhirnya pasar bereaksi terhadap informasi tersebut dan harga-harga saham mengalami penyesuaian sehingga dapat dikatakan bahwa secara tidak langsung peristiwa politik memengaruhi aktivitas di pasar modal Indonesia (Dinantara \& Yasa, 2021). Peristiwa reshuffle kabinet dapat memengaruhi harga saham baik positif maupun negatif, tergantung dari persepsi masing-masing investor dan caloninvestor (Asshodiqi, 2016).

Pada tanggal 22 Desember 2020, Presiden Joko Widodo memperkenalkan 6 calon menteri Kabinet Indonesia Maju di beranda belakang Istana Merdeka, Jakarta. Pada hari berikutnya tanggal 23 Desember 2020 pelantikan menteri dan wakil menteri Kabinet Indonesia Maju periode 2019-2024 dilakukan (Matsuzawa \& Sari, 2020). Adapun 6 kementerian yang dirombak oleh Presiden adalah Kementerian Kelautan dan Perikanan, Kementerian Sosial, Kementerian Pariwisata dan Ekonomi Kreatif, Kementerian Kesehatan, Kementerian Agama, dan Kementerian Perdagangan. Pelantikan para menteri negara sisa masa jabatan periode tahun 2019-2024 ini berdasarkan Surat Keputusan Presiden Republik Indonesia Nomor 133/P Tahun 2020 tentang Pengisian dan Penggantian Beberapa Menteri Negara Kabinet Indonesia Maju Periode Tahun 2019-2024 yang dibacakan oleh Sekretaris Kementerian Sekretariat Negara. Sebelumnya terdapat 2 menteri yang tersandung kasus tindak pidana korupsi, yaitu menteri kelautan dan perikanan Edhy Prabowo yang tersandung kasus suap ekspor benih lobster. Serta itu ada juga menteri sosial Jualiari Peter Batubara yang tersandung kasus suap dana bantuan sosial Covid-19. Kekosongan jabatan tersebut mengharuskan Presiden Joko Widodo untuk segera mengisi dan mengganti kembali jabatan pada kementeriantersebut. Pergantian menteri dan wakil menteri tersebut diharapkan dapat berkeja samadalam membangun kerja tim dan mampu untuk beradaptasi secara cepat ditengah tantangan besar akibat adanya pandemi Covid-19 (I. G. B. Y. P. Putra \& Suarjaya, 2020). 
Berhubungan dengan peristiwa pelantikan kabinet Indonesia maju hasil reshuffle jilid I tahun 2020 pada tanggal 23 Desember 2020, IHSG menunjukkan terdapat perubahan harga saham seperti pada gambar 1.1, menurut Ulfa (2020) pada tanggal 23 desember IHSG ditutup melemah 14,58 poin atau 0,24 persen ke level 6.008,70. Indeks dibuka menguat tajam 1 persen sebelum terjungkal turun 2 persen di sesi pertama. Berdasarkan data Bloomberg, sebanyak 173 saham menguat, 309 saham melemah, dan 227 saham stagnan. Secara sektoral, 6 sektor melemah sedangkan sisanya menguat. Sektor consumer, aneka industri, dan pertambangan menjadi pemberat indeks. IHSG di awal perdagangan sempat terpantau naik tajam 66 poin atau 1,1 persen $\mathrm{ke}$ level 6.089,69. Indeks dibuka di level 6.061,85 lebih dan sempat menyentuh level 6.104,36. Namun, tidak berselang lama, IHSG tumbang, melorot 2 persen dan terjun ke bawah level 6.000 . Sejalan dengan hal tersebut, saham-saham terindeks LQ45 saat penutupan berada di zona merah pada posisi 93,795. Dengan saham-saham yang mengalami kenaikan sebesar 15 saham dan yang mengalami penurunan sebesar 30 saham. Pada penutupan ini, asing yang aktif membeli beberapa saham seperti PT Aneka Tambang Tbk (ANTM), PT Smartfren Telecom Tbk (FREN), PT Waskita Beton Precast Tbk (WSBP). Saham-saham yang mencetak net sell pada penutupan 23 Desember 2020 adalah PT Sarana Menara Nusantara Tbk (TOWR), PT Bank Rakyat Indonesia (Persero) Tbk (BBRI), PT Global Mediacom Tbk (BMTR)

Penelitian ini dilakukan untuk memastikan apakah terdapat atau tidaknya reaksi pasar modal terhadap peristiwa pelantikan kabinet Indonesia Maju hasil reshuffle jilid I tahun 2020 dengan menggunakan event study (Pratiwi \& Wirama, 2021). Event study merupakan studi yang mempelajari reaksi pasar terhadap suatu peristiwa (event) yang informasinya dipublikasi sebagai suatu pengumuman. Adanya reaksi pasar disebabkan denganperubahan harga dan volume perdagangan dari sekuritas bersangkutan. Abnormal return atau excess return merupakan adanya kelebihan dari return yang sesungguhnya terjadi terhadap return normal (Repousis, 2016). Suatu pengumuman menimbulkan reaksi pasar akan memberikan abnormal return kepada pasar dan sebaliknya. Terdapat beberapa penelitian sebelumnya yang meneliti mengenai reaksi pasar terhadap informasi eksternal berupa regulasi baru yang dikeluarkan oleh pemerintah, kesepakatan atau kerja sama yang dibuat pemerintah, pemilihan umum presiden maupun peristiwa lainnya yang dapat berpengaruh terhadap tingkat kestabilan kondisi perekonomian pada suatu negara (Xiao \& Gao, 2017).

Subawa \& Mimba (2020), meneliti tentang Reaksi Pasar Atas Pengumuman Hasil Pemilihan Kabinet Kerja Jilid II Presiden Indonesia Tahun 2019 yang mendapatkan hasil yaitu terdapat reaksi pasar saat Pengumuman Hasil Pemilihan Kabinet Kerja Jilid II Presiden Indonesia tahun 2019. Hasil serupa juga terdapat pada penelitian Saraswati \& Mustanda (2018) meneliti Reaksi Pasar Modal Indonesia terhadap PeristiwaPengumuman Hasil Penghitungan Suara Pemilihan Umum dan Pelantikan Presiden Amerika Serikat memperoleh hasil yaitu terdapat perbedaan abnormal return sebelum dan setelah peristiwa pengumuman hasil penghitungan suara pemilihan umum Presiden Amerika Serikat dan terdapat perbedaan abnormal return sebelum dan setelah peristiwa pelantikan Presiden Amerika Serikat. Hasil berbeda didapatkan Prameswari \& Wirakusuma (2018), meneliti tentang reaksi pasar modal Indonesia terhadapperistiwa pemilihan gubernur DKI Jakarta tahun 2017 yang mendapatkan hasil yaitu tidak terdapat perbedaan rata-rata abnormal return dan trading volume activity sebelum dan sesudah pemilihan gubernur DKI Jakarta tahun 2017. Hatmanti \& Sudibyo (2017), meneliti tentang Pengaruh Pelantikan Kabinet Kerja Hasil Reshuffle Jilid II terhadap Harga Saham LQ-45 yang mendapatkan hasil tidak menunjukkan adanya hasil yang signifikan. Kemudian hipotesis yang dikembangkan dalam penelitian ini adalah terdapat perbedaan reaksi pasar modal sebelum dan sesudah peristiwapelantikan kabinet Indonesia Maju hasil reshuffle jilid I tahun 2020 


\section{METODE PENELITIAN}

Dalam penelitian ini mengasumsikan pasar modal Indonesia sudah efisien dalam bentuk setengah kuat, hal ini dikarenakan pasar modal Indonesia masih berkembang. Pada penelitian ini menggunakan metode periode pendek (short event window) selama 6 hari yang terdiri dari 3 hari sebelum peristiwa pelantikan kabinet Indonesia Maju hasil reshuffle jilid I tahun 2020 dilaksanakan (t3), 1 hari saat pelantikan kabinet Indonesia Maju hasil reshuffle jilid I tahun 2020 (t0), dan 3 hari sesudah pelantikan kabinet Indonesia Maju hasil reshuffle jilid I tahun 2020 dilaksanankan $(\mathrm{t}+3)$. Penelitimenilai dengan menggunakan 6 hari merupakan jumlah yang tepat untuk mengetahui respon dari para investor atas terjadinya pengumuman suatu peristiwa.

Tanggal publikasi peristiwa pada penelitian ini adalah pada tanggal 23 Desember2020. Oleh karena itu, penelitian ini menetapkan tanggal peristiwa pada tanggal 23 Desember 2020. Lokasi penelitian ini dilakukan di Bursa Efek Indonesia (BEI) pada saham terindeks LQ45 karena sahamnya memiliki karakteristik dengan tingkat likuiditas tinggi sehingga mudah untuk diperdagangkan dan memiliki kapitalitasi pasardi BEI yang relatif besar. Populasi dalam penelitian ini adalah saham-saham yang terdaftar dalam saham terindeks LQ45 di Bursa Efek Indonesia. Alasan menggunakan saham-saham terindeksLQ45, karena sahamnya memiliki karakteristik dengan tingkat likuiditas tinggi sehingga mudah untuk diperdagangkan dan memiliki kapitalisasi pasar di Bursa Efek Indonesia yang relatif besar. Dengan menggunakan saham terindeks LQ45 diharapkan dapat mewakili pasar dan dapat memperoleh hasil yang mencerminkan reaksi pasar modal Indonesia secara menyeluruh dan lebih akurat terhadap peristiwa pelantikan kabinet Indonesia Maju hasil reshuffle jilid I tahun 2020

Metode penentuan sampel yang digunakan adalahmetode nonprobability sampling dengan menggunakan teknik purposive sampling. Pengambilan sampel dalam penelitian ini didasarkan atas pertimbangan Jajaran saham yang termasuk di dalam saham terindeks LQ45 bulan Desember 2020 di Bursa Efek Indonesia dan Tidak melaksanakan corporate action yaitu stock split, pengumuman dividen, right issue, saham bonus dan penerbitan warrant pada periode pengamatan atau jendela peristiwa penelitian yaitu bulan Desember 2020 untukmenghindari confounding effect agar sampel penelitian terfokus pada peristiwa pelantikan kabinet Indonesia Maju hasil reshuffle jilid I tahu 2020 dan bukan peristiwa lainnya. Metode pengumpulan data yang digunakan dalam penelitian ini adalah metode penelitian arsip (archival research). Uji t-signifikansi yang digunakan pada penelitian ini yaitu paired sample $t$-test, metode uji paired sample $t$-test selama 6 hari periode peristiwa. Jumlah populasi pada penelitian yaitu sebanyak 45 perusahaan LQ45 yang terdaftar di Bursa Efek Indonesia, namun terdapat 2 perusahaan melakukan corporate action yaitu PT. Bank Mandiri (Persero) Tbk. dan PT. Surya Citra Media Tbk. melakukan corporate action berupa pembagian dividen untuk menghindari confounding effect agar sampel penelitian terfokus pada peristiwa pelantikan kabinet Indonesia Maju hasil reshuffle jilid I tahun 2020 dan bukan persitiwa lainnya. 


\section{HASIL DAN PEMBAHASAN}

Deskripsi statistik merupakan bagian awal dari analisis data yang memberikan gambaran awal mengenai masing-masing variabel penelitian cumulative abnormal return. Penyajian statistik deskriptif pada penelitian ini bertujuan untuk memberikan informasi mengenai karakteristik variabel penelitian berupa jumlah sampel, nilai rata-rata, nilai minimum dan nilai maksimum, serta nilai deviasi standar. Hasil analisis statistik deskriptif yang akan diuji untuk variabel penelitian cumulative abnormal return (CAR) berjumlah 43 sampel perusahaan.

Tabel 1.

Statistik Deskriptif Cumulative Abnormal Return Sebelum dan SesudahPeristiwa

\begin{tabular}{lccccc}
\hline Variabel & Jumlah & Minimum & Maksimum & Rata-Rata & $\begin{array}{l}\text { Std. } \\
\text { Deviation }\end{array}$ \\
& & & & & \\
\hline CAR Sebelum & 43 & $-0,190$ & 0,150 & 0,056 & 0,052 \\
\hline CAR Sesudah & 43 & $-0,090$ & 0,080 & 0,007 & 0,035 \\
\hline
\end{tabular}

Sumber: Datadiolah, 2021

Tabel 1 menjelaskan nilai minimum, maksimum, rata-rata, dan standar deviasisebelum dan sesudah peristiwa pelantikan kabinet Indonesia Maju hasil reshuffle jilid I tahun 2020. Berdasarkan tabel 4.2 nilai cumulative abnormal return (CAR) sebelum peristiwa menunjukan rata-rata sebesar 0,056 dengan standar deviasi sebesar 0,052. Nilai CAR sebelum peristiwaterendah sebesar -0,190 dan nilai CAR sebelum peristiwatertinggi sebesar 0,150 . Nilai cumulative abnormal return (CAR) sesudah peristiwa menunjukan rata-rata sebesar 0,007 dengan standar deviasi 0,035. Nilai CAR sesudah peristiwa terendah sebesar $-0,090$ dan nilai CAR sesudah peristiwa tertinggi sebesar 0,080 . rata-rata CAR sebelum peristiwa $(\mathrm{t}=0)$ sebesar 0,056 , nilai tersebut lebih besar daripada nilai sesudah peristiwa $(\mathrm{t}=1)$ pelantikan kabinet Indonesia Maju hasil reshuffle jilid I tahun 2020 sebesar 0,007. Hasil analisis ini menunjukkan bahwa CAR mengalami penurunan dengan adanya peristiwa pelantikan kabinet Indonesia Maju hasil reshuffle jilid I tahun 2020.

Tabel 2

Pengujian Normalitas Cumulative Abnormal Return Sebelum dan SesudahPeristiwa

\begin{tabular}{cccc}
\hline Variabel & Jumlah & Sig (2-Tailed) & Kriteria \\
\hline CAR Sebelum & 43 & 0,00 & 0,05 \\
& & & 0,05
\end{tabular}

Sumber: Datadiolah, 2021 
Berdasarkan tabel 2 nilai signifikansi Kolmogorov-smirnov variabel Cumulative Abnormal Return (CAR) sebelum peristiwa adalah sebesar 0,00 dansesudah peristiwa sebesar 0,00 yang nilainy a di bawah kriteria 0,05 maka berarti variabel CAR sebelum dan sesudah peristiwa berdistribusi tidak normal sehingga pengujian hipotesis selanjutnya dengan menggunakan statistik parametrik, yaitu Wilcoxon Signed Rank Test.

Tabel 3.

Hasil Uji Wilcoxon Signed Rank Test Abnormal Return Sebelum dan SesudahPeristiwa

Abnormal return sebelum dan sesudah

\begin{tabular}{lc}
\hline $\mathrm{Z}$ & $-4,818$ \\
\hline Sig (2-Tailed) & 0,000 \\
\hline
\end{tabular}

Sumber: Datadiolah, 2021

Berdasarkan Tabel 3 abnormal return sebelum dan sesudah peristiwa menunjukan nilai signifikasnsi sebesar 0,00 . Nilai signifikansi dibawah 0,05 menunjukan bahwa adanya perbedaan yang signifikan. Sehingga dapat disimpulkan bahwa hipotesis diterima, hal ini berarti terdapat perbedaan abnormal return sebelum dan sesudah peristiwa pelantikan kabinet Indonesia Maju hasil reshuffle jilid I tahun 2020 pada tanggal 23 Desember 2020 atau dengan kata lain peristiwa pelantikan kabinet Indonesia Maju hasil reshuffle jilid I tahun 2020 pada tanggal 23 Desember 2020 memiliki kandungan informasi sehingga investor bereaksi terhadap informasi tersebut.

Penelitian ini merupakan event study pada peristiwa pelantikan kabinet IndonesiaMaju hasil reshuffle jilid I tahun 2020. Menurut hasil pengujian menunjukkan terdapat perbedaan rata-rata abnormal return sebelum dan sesudah peristiwa pelantikan kabinet Indonesia Maju hasil reshuffle jilid I tahun 2020 tanggal 23 Desember 2020. Hasil ini sesuai dengan hipotesis (Ha). Nilai CAR sebelum peristiwa adalah 0,056 dan nilai CARsesudah peristiwa adalah 0,007, hasil ini menunjukan nilai CAR sebelum peristiwa lebih tinggi daripada CAR sesudah peristiwa. Penurunan abnormal return setelah peristiwa pelantikan kabinet Indonesia Maju hasil reshuffle jilid I tahun 2020 signifikankarena pasar menganggap peristiwa ini mengandung informasi yang negatif untuk emiten, dengan kata lain investor menganggap informasi peristiwa pelantikan kabinet Indonesia Maju hasil reshuffle jilid I tahun 2020 sebagai bad news. Hal ini memperlihatkan bahwa terdapat reaksi pasar pada saat peristiwa pelantikan kabinet Indonesia Maju hasil reshuffle jilid I tahun 2020 yang ditunjukkan dengan adanya abnormal return yang signifikan. Berdasarkan hasil tersebut dapat dikatakan bahwa peristiwa pelantikan kabinet Indonesia Maju hasil reshuffle jilid I tahun 2020 tanggal 23 Desember 2020 cukup untuk menggerakkan investor dalam pengambilan keputusan investasinya. Investor dalam melakukan pertimbangan investasi tidak hanya memperhitungkan teknik analisis fundamental seperti melihat kinerja perusahaan, tetapi juga mempertimbangkan peristiwa disekitarnya, seperti peristiwa ekonomi dan non-ekonomi untuk memperoleh return dan terhindar dari risiko kerugian investasi. Hasil penelitian ini mengandung teori efisiensi pasar dimana pasar merespon informasi-informasi yang masuk dan bagaimana informasi tersebut selanjutnya bisa mempengaruhi pergerakan harga sekuritas menuju harga keseimbangan yang baru

Hasil penelitian ini serupa dengan penelitian yang dilakukan oleh Subawa \& Mimba (2020), $\underline{\text { menyatakan bahwa terdapat reaksi pasar saat pengumuman hasil pemilihan kabinet kerja jilid II }}$ 
Presiden Indonesia tahun 2019. Hasil serupa juga terdapat pada penelitian Saraswati \& Mustanda (2018) meneliti Reaksi Pasar Modal Indonesia terhadap Peristiwa Pengumuman Hasil Penghitungan Suara Pemilihan Umum dan Pelantikan Presiden Amerika Serikat memperoleh hasil yaitu terdapat perbedaan abnormal return sebelum dan setelah peristiwa pengumuman hasil penghitungan suara pemilihan umum Presiden Amerika Serikat dan terdapat perbedaan abnormal return sebelum dan setelah peristiwa pelantikan Presiden Amerika Serikat. Informasi yang relevan dengan kondisi pasar modal merupakan sesuatu yang selalu dicari para pelaku pasar modal dalam upaya melakukan pengambilan keputusandalam berinvestasi. Informasi yang tersebar tidak semua merupakan informasi yang berharga, akibatnya para pelaku pasar modal harus secara tepat memilah informasi- informasi yang layak (relevan) dijadikan pertimbangan pengambilan keputusan. Peristiwa pelantikan kabinet Indonesia Maju hasil reshuffle jilid I tahun 2020 menunjukkan adanya reaksi yang diukur dengan abnormal return sebelum dan sesudah peristiwa.

Hasil penelitian ini dapat menjadi pertimbangan bagi investor untuk lebih berhati-hati dengan peristiwa ekonomi maupun non-ekonomi. Setiap informasi yang diterima oleh pelaku pasar diharapkan dianalisis terlebih dahulu berdasarkan pertimbangan dan karakteristik masing-masing investor, sehingga pelaku pasar modal dapat mengambil keputusan investasi agar mendapatkan pengembalian yang maksimal. Hasil penelitian ini dapat memberikan gambaran mengenai bagaimana pelaku pasar bertindak pada saat peristiwa non-ekonomi pelantikan kabinet Indonesia Maju hasil reshuffle jilid I tahun 2020.

\section{SIMPULAN DAN SARAN}

Berdasarkan hasil pengujian hipotesis, ditemukan bahwa terdapat perbedaan yang signifikan abnormal return sebelum dan sesudah peristiwa pelantikan kabinet Indonesia Maju hasil reshuffle jilid I tahun 2020 terhadap jajaran saham perusahaan terindeks LQ45 yang terdaftar di BEI. Hal ini terjadi karena peristiwa pelantikan kabinet Indonesia Maju hasil reshuffle jilid I tahun 2020 terdapat kandungan informasi sehingga pasar membutuhkan waktu cepatdalam pencapaian keseimbangan baru. Investor dalam penelitian ini bereaksicepat dalam menyerap informasi sehingga sesuai dengan pasar efisien bentuksetengah kuat. Bagi investor, diharapkan penelitian ini dapat menjadi masukan atau pertimbangan sebelum melakukan investasi di pasar modal berdasarkan peristiwa yang terjadi khususnya terkait peristiwa pelantikan kabinet Indonesia Maju hasil reshuffle jilid I tahun 2020. Bagi peneliti selanjutnya diharapkan bisa menggunakan peristiwa ekonomi maupun non-ekonomi lainnya untuk menguji kandungan informasi dan menjelaskan reaksi pasar pada peristiwa tersebut.

Hasil penelitian ini dapat menjadi pertimbangan bagi investor untuk lebih berhati-hati dengan peristiwa ekonomi maupun non-ekonomi. Setiap informasi yang diterima oleh pelaku pasar diharapkan dianalisis terlebih dahulu berdasarkan pertimbangan dan karakteristik masing-masing investor, sehingga pelaku pasar modal dapat mengambil keputusan investasi agar mendapatkan pengembalian yang maksimal. Hasil penelitian ini dapat memberikan gambaran mengenai bagai mana pelaku pasar bertindak pada saat peristiwa non-ekonomi pelantikan kabinet Indonesia Maju hasil reshuffle jilid I tahun 2020. 


\section{REFERENSI}

Aryasa, I. P. G. C. A., \& Suaryana, I. G. N. A. (2017). Reaksi Pasar Sebelum dan Sesudah Pengumuman Right Issue. EJurnal Akuntansi Universitas Udayana, 18(3), 1426-1454.

Asshodiqi, A. (2016). Reaksi Pasar Modal Terhadap Peristiwa Pelantikan Presiden Tahun 2014(Event Study Pada Sah am LQ45, JII dan SMINFRA18). Jurnal Ilmiah Mahasiswa FEB, 3(2), 1-10.

Chandra, I. W. A., \& Suardana, K. A. (2021). Market Reaction Before and After Coronavirus Disease-2019 Announcement in Indonesia on Pharmaceutical Sub Sector Companies. American Journal of Humanities and Social Sciences Research (AJHSSR), 5(6), 419-424.

Dinantara, I. G. O., \& Yasa, G. W. (2021). Market Reaction about the Spread of Covid-19 in Indonesia ( Study on LQ45 Stock Index ). American Journal of Humanities and Social Sciences Research (AJHSSR), 1(6), 190-193.

Fama, E. (1970). Efficient Capital Markets - A review of theory and empirical work. Journal of Finance, $25(2), 1$.

Fiordelisi, F., \& Galloppo, G. (2018). Stock market reaction to policy interventions. European Journalof Finance, 1(1), 1-18. https://doi.org/https://doi.org/10.1080/1351847X.2018.1450278

Gayatri, \& Sari, P. (2018). Perbedaan Abnormal Return Sebelum dan Sesudah Pemilihan Umum Gubernur DKI Jakarta Tahun 2017. E-Jurnal Akuntansi Universitas Udayana, 24(2), 1-12.

Hall, S. G., \& Kenjegaliev, A. (2016). The Effect of Oil Price Changes on The Price of Russian and Chinese Oil Shares. Empirical Economics, 1(1), 1-18. https://doi.org/https://doi.org/10.1007/s00181-016-1176-3

Hatmanti, A., \& Sudibyo, B. (2017). Pengaruh Pelantikan Kabinet Kerja Hasil Reshuffle Jilid Ii Terhadap Harga Sah am Lq 45. Jurnal Economia, 13(1), 1. https://doi.org/https://doi.org/10.21831/economia.v13i1.11797

Juliani, S. A. P., \& Sari, M. M. R. (2021). Capital Market Reaction on Rights Issue Announcement. American Journal of Humanities and Social Sciences Research (AJHSSR), 5(2), 372-377.

Matsuzawa, G, P, D., \& Sari, M, M, R. (2020). Reaksi Pasar Terhadap Peristiwa Pelantikan Presiden dan Wakil Presiden Tahun 2019. E-Jurnal AKUNTANSI, 8(2), 85-92. https://doi.org/https://doi.org/10.24843/EJA.2020.vxx.ixx.pxx

Mujib, B., \& Candraningrat, I. R. (2021). Capital Market Reaction to Covid-19 Pandemic on LQ45 Shares at Indonesia Stock Exchange (IDX). American Journal of Humanities and Social Sciences Research (AJHSSR), 5(3), 74-80.

Nia, V. M. (2020). The Effect of Corona Outbreak on the Indonesian Stock Market Jakarta Stock Exhange. American Journal of Humanities and Social Sciences Research (AJHSSR), 4(3), 358-370.

Nuryana, I. (2017). Analisis Reaksi Pasar Modal Terhadap Pengangkatan Joko Widodo Sebagai Presiden Republik Indonesia. Jurnal Ilmu Manajemen Dan Akuntansi, 4(2), 1-14. https://doi.org/https://doi.org/10.33366/ref.v4i2.517

Osuala, A. E., Onoh, U. A., \& Nwansi, G. U. (2018). Presidential Election Results and Stock Market Performance: Evidence From Nigeria. Applied Economics and Finance, 5(2), 117-124.https://doi.org/https://doi.org/10.11114/aef.v5i2.3016

Prameswari, I. A. N., \& Wirakusuma, M. G. (2018). Analisis Reaksi Pasar Modal Pada Peristiwa Pemilihan Gubernur DKI Jakarta Tahun 2017. E-Jurnal Akuntansi Universitas Udayana, 22(2), 944-975.

Pramiartini, S. A. P. M., \& Sedana, I. B. P. (2021). Stock Market Reaction to Corona Outbreak in Indonesia ( Stu dy on The Tourism Industry in Indonesia Stock Exchange ). American Journal of Humanities and Social Sciences Research (AJHSSR), 25(1), 624-630.

Pratiwi, G. A. E., \& Wirama, D. G. (2021). Market Reactions to the Implementation of Large-Scale Social Restrictions Phase 1 in Jakarta. American Journal of Humanities and Social Sciences Research (AJHSSR), 5(5), 227-231.

Putra, R. E. P., \& Wirawati, N. G. P. (2019). Reaksi Pasar Terhadap Pelemahan Nilai Rupiah Pada Nilai Tukar US Dollar. EJurnal Akuntansi, 28(2), 214-241. https://doi.org/https://doi.org/10.24843/EJA.2019.v28.i01.p09.

Putra, I. G. B. Y. P., \& Suarjaya, A. A. G. (2020). Analysis of Market Reaction to Announcements Of Stock Split. American Journal of Humanities and Social Sciences Research, 4(6), 114-120. www.ajhssr.com

Repousis, S. (2016). Abnormal stock returns in Greece during the Cypriot banking crisis. Journal of Money Laundering Control, 19(2), 122-129. https://doi.org/https://doi.org/10.1108/JMLC-04-2015-0015

Saraswati, N. M. A. W., \& Mustanda, I. K. (2018). Reaksi Pasar Modal Indonesia Terhadap Peristiwa Pengumuman Ha sil Penghitungan Suara Pemilihan Umum Dan Pelantikan Presiden Amerika Serikat. E-Jurnal Manajemen Universitas Udayana, 7(6), 2971-2998. https://doi.org/https://doi.org/10.24843/ejmunud.2018.v07.i06.p05

Subawa, I. G. P., \& Mimba, N. P. S. . (2020). Reaksi Pasar Atas Pengumuman Hasil Pemilihan Kabinet Kerja Jilid II Presiden Indonesia Tahun 2019. E-Jurnal Akuntansi, 30(11), 2852-2863, 
https://doi.org/https://doi.org/10.24843/EJA.2020.v30.i11.p1 1

Suhadak, S., Kurniaty, K., Handayani, S. R., \& Rahayu, S. . (2019). Stock return and financial performance as moderation variable in influence of good corporate governance towards corporate value. Asian Journal of Accounting Research, 4(1), 18-34.https://doi.org/https://doi.org/10.1108/AJAR-07-2018-0021

Xiao, X., \& Gao, Y. (2017). An Event Study of The Effects of Regulatory Changes on The Food Industry. China Agricultural Economic Review, 9(1), 81-92. https://doi.org/https://doi.org/10.1108/CAER-01-2014-0006

Yasa, G. E., \& Sari, M. M. R. (2020). Analysis of Market Reaction on Wall Street Attenuation in Indonesia. American Journal of Humanities and Social Sciences Research (AJHSSR), 4(8), 475-481. 